\title{
Seasonal interest in pectus excavatum and pectus carinatum: a retrospective analysis of Google Trends data
}

\author{
Piotr Skrzypczak $^{1}$, Mikołaj Kamiński ${ }^{2} \wedge$, Krystian Pawlak ${ }^{1}$, Cezary Piwkowki ${ }^{1}$ \\ ${ }^{1}$ Department of Thoracic Surgery, Poznan University of Medical Sciences, Poznań, Poland; ${ }^{2}$ District Hospital in Oborniki, Oborniki, Poland \\ Contributions: (I) Conception and design: P Skrzypczak, M Kamiński; (II) Administrative support: K Pawlak, C Piwkowki; (III) Provision of study \\ materials or patients: M Kamiński; (IV) Collection and assembly of data: P Skrzypczak, M Kamiński; (V) Data analysis and interpretation: All authors; \\ (VI) Manuscript writing: All authors; (VII) Final approval of manuscript: All authors. \\ Correspondence to: Piotr Skrzypczak, MD. Department of Thoracic Surgery, Poznan University of Medical Sciences, Szamarzewskiego 62 , $60-569$ \\ Poznań, Poland. Email: piotr.j.skrzypczak@gmail.com.
}

\begin{abstract}
Background: Individuals affected by chest wall deformities may search for information on these conditions on the web. Google data may reflect the global interest in health-related information. Our aim was to investigate the global trends in searches associated with the topics "Pectus excavatum" and "Pectus carinatum" using Google Trends.

Methods: We retrieved the global data from 1st January 2004 to 31st October 2019. We analyzed the relative search volume (RSV) for countries or areas with a no-low search volume. We compared differences in interest between seasons using the Kruskal-Wallis test with the post-hoc test.

Results: The median RSV for the pectus excavatum was equal to 58.00 (54.00-65.00) while for pectus carinatum 28.00 (23.25-31.00). The interest in pectus excavatum decreases on average by 0.98 RSV each year, while interest in pectus carinatum increased each year by $0.87 \mathrm{RSV}$. We observed the highest interest in analyzed topics during summer and the lowest during winter. The relative difference in interest between summer and winter was equal to $21.4 \%$ for pectus excavatum and $19.2 \%$ for pectus carinatum. Pectus excavatum was the most popular topic in $n=51$ countries or areas, while pectus carinatum in $n=7$ countries or areas/regions.

Conclusions: Globally, interest in pectus excavatum is higher than the interest in pectus carinatum that might reflect real-world prevalence. The interest in both topics shows seasonal variation. The Internet is an essential source of information on chest wall deformities. The medical professionals should provide quality content on pectus excavatum and pectus carinatum.
\end{abstract}

Keywords: Seasonal variation; pectus excavatum; pectus carinatum; Nuss procedure; Google Trends

Submitted Sep 19, 2020. Accepted for publication Dec 10, 2020.

doi: $10.21037 /$ jtd-20-2924

View this article at: http://dx.doi.org/10.21037/jtd-20-2924

\section{Introduction}

Pectus excavatum (PE) and pectus carinatum (PC) account for $95-97 \%$ of all chest wall deformities. PE affects $0.1 \%$ of all live births, while $\mathrm{PC}$ is less common and occurs in $0.06 \%$ $(1,2)$. They have aroused doctors' interest for centuries due to their unclear origin and challenging treatment (3). Chest wall deformities lower the quality of life to the highest degree in the adolescent population. Compared to healthy individuals, patients with $\mathrm{PE}$ or PC are characterized by lower quality of life in the mental and physical sphere. These deformities both significantly disturb the individual's self-body image. Moreover, they may cause physical

^ ORCID: Piotr Skrzypczak, 0000-0002-7056-4472; Mikołaj Kamiński, 0000-0002-4394-0460. 


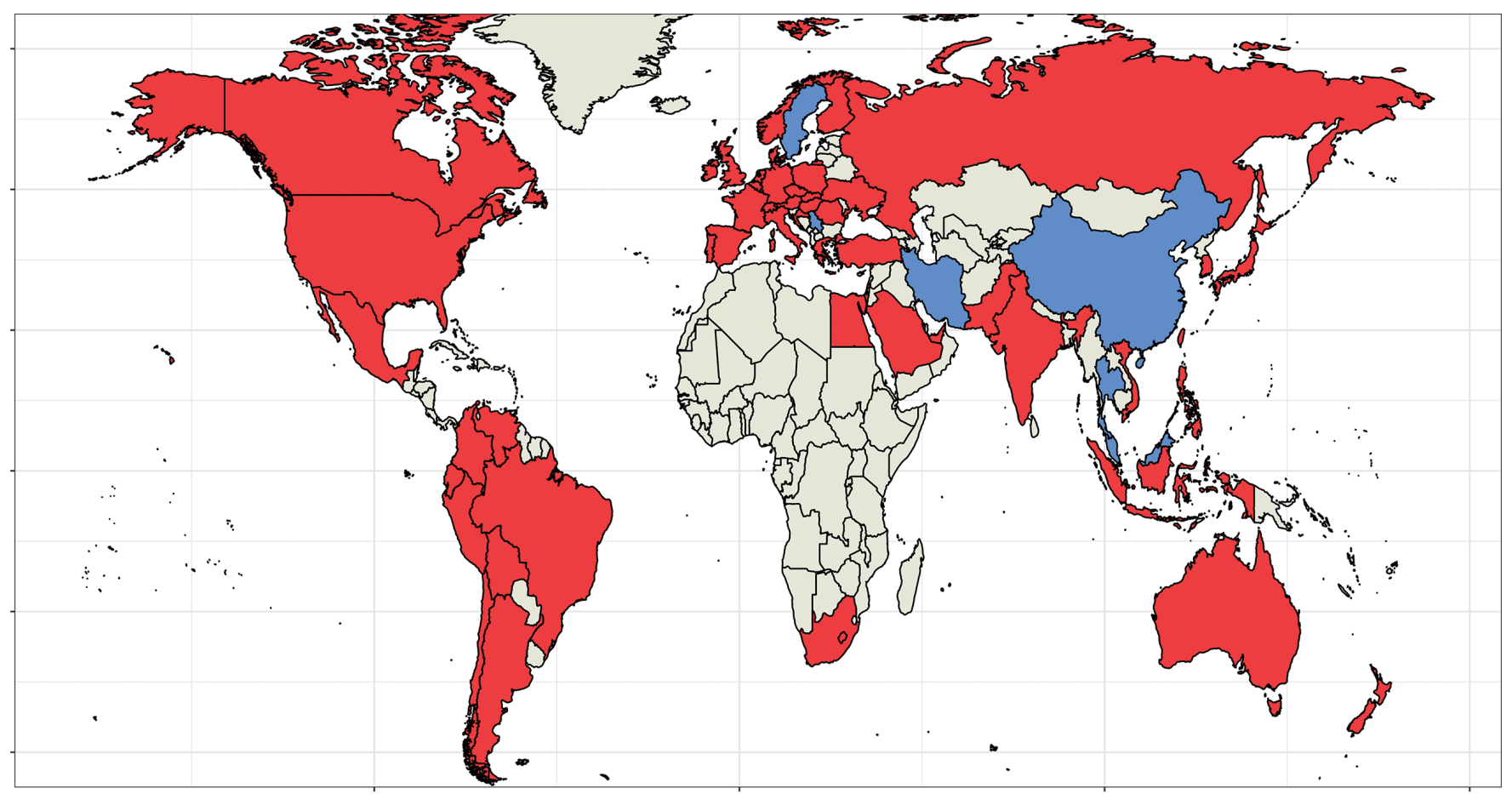

Topic $\square$ Pectus carinatum $\square$ Pectus excavatum $\square$ Low search volume

Figure 1 Global interest in "Pectus carinatum" and "Pectus excavatum" from January 2004 through October 2019. The gray color represents countries or areas with a low search volume, which were not included in the analysis.

disorders (dyspnoea, chest pain, and palpitations) (4-6). Both cosmetic and functional impairments are the main inclusion criteria for correction (4,7-10).

Individuals affected by $\mathrm{PE}$ or PC may search for information on chest deformities on the Internet, which is used daily by the young generation. Internet traffic may mirror the interests of the population in health issues (11). Analysis of search engine queries enables one to estimate the interest in various medical issues and depict the specific data circulation worldwide (12). We hypothesize that the analysis of searches on chest wall deformities may reveal an under-researched phenomenon related to the dynamics and local distribution of interest. Google is one of the best search engines globally, and in 2019 acquired over 90 percent of the global search engine market (13). Therefore, we decided to use data from Google Trends (GT; https://trends.google.com/trends/).

This study was the first to assess the interest of internet users in PE and PC. Our study aimed to assess the global interest, its secular and seasonal trends, in the years 2004-2019 in the topics "Pectus excavatum" and "Pectus carinatum" among Google users.

\section{Methods}

We retrieved the data from GT. GT presents the data on Google queries since January 2004. The tool is freely available. The search volume is expressed as an index called relative search volume (RSV). RSV is an index and ranges from 0 (no interest) to 100 (maximum interest in a given period). RSV is also adjusted for the number of Google users in a given month. GT recognizes many "topics" that enable the analysis of RSV of the same "topic" in all languages. It facilitates the easy comparison of the given terms regardless of the language of Google users.

This study follows the GT data processing protocol from previous studies $(12,14,15)$. We retrieved data for the period from 1st January 2004 to 31st October 2019. We obtained data for the PC and PE topics from regions worldwide, respectively. The search term "Funnel chest" matches the topic PE, while "Pigeon chest" does not match any topic. We visualized the most popular topic in each analyzed country and analyzed the relative popularity presented by GT (Figure 1). Data from countries or areas with low search volumes has been excluded using the relevant GT option. 


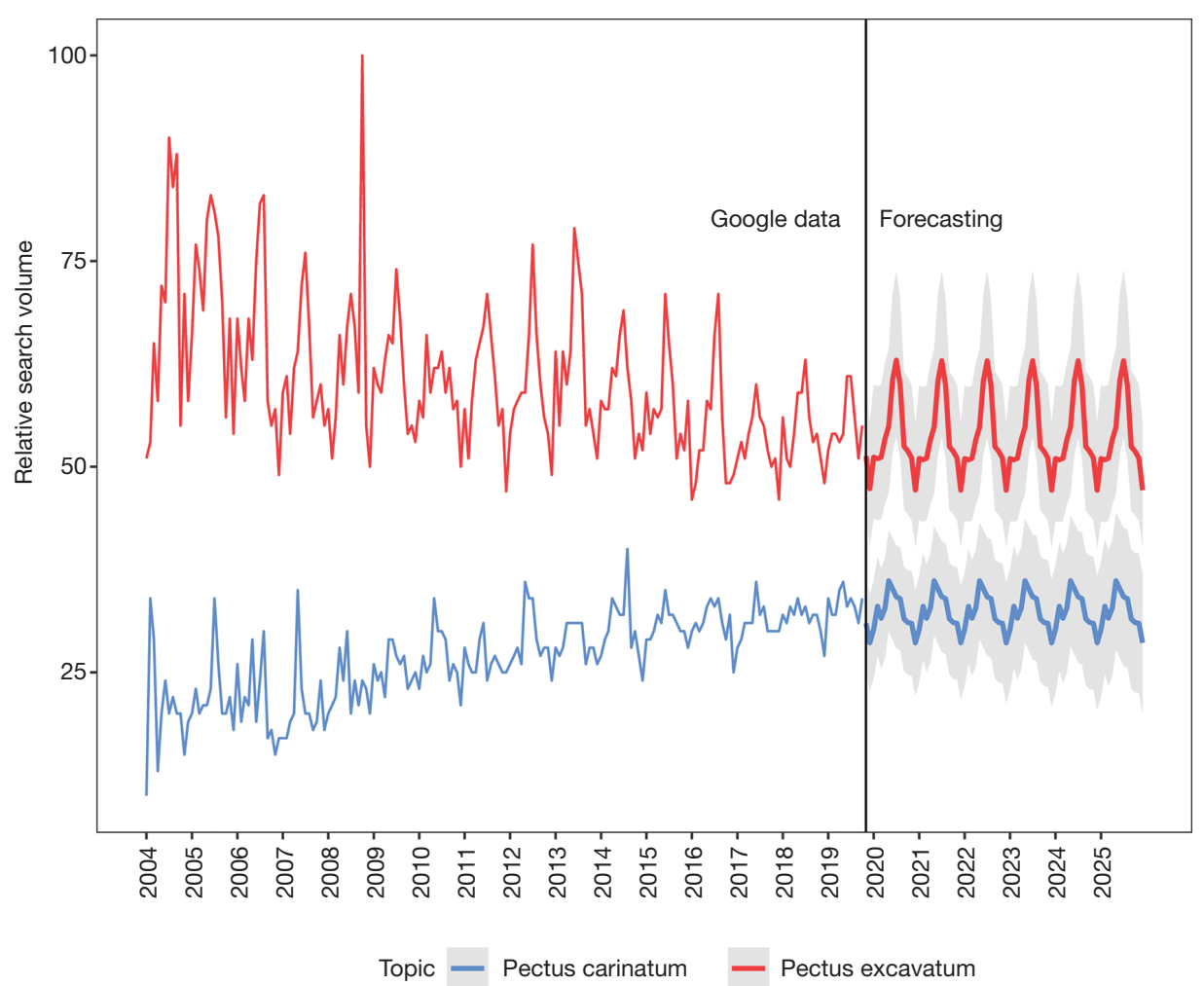

Figure 2 Relative search volume (RSV) of the "Pectus carinatum" and "Pectus excavatum" topics worldwide from January 2004 through October 2019 and forecasted model until December 2025.

In seasonal analyze we considered the following seasons: spring (March, April, May), summer (June, July, August), autumn (September, October, November), and winter (December, January, February). We calculated the relative amplitude between the season with the highest and the lowest $\mathrm{RSV}$ and expressed the outcome as a percentage (Figure 2).

Most of the Google users live in the Northern Hemisphere. For this reason, seasonal variation may have an association with the season in the northern part of the globe $(12,16)$. Therefore, we analyzed both the PC and PE topics in two countries or areas from the Southern Hemisphere: Argentina and Australia. We performed a comparison of RSV between the season in Argentina and Australia with the Northern Hemisphere.

Moreover, we search for the presence of "Nuss procedure" and "Ravitch procedure" as topics. Only the "Nuss procedure" was matched by GT as a topic. We retrieved the global data for the "Nuss procedure" and PE topics. We excluded countries or areas with a low search volume. We searched for discrepancies between the number of countries or areas with a no-low search volume on both topics (Figure 1).

\section{Statistical analysis}

Furthermore, we performed a descriptive analysis and forecasting until 31st December 2025 using an exponential smoothing state-space model with Box-Cox transformation, autoregressive-moving average errors, trend, and the seasonal components (TBATS) method from Kendall and forecast packages of the R-programming language $(16,17)$. We calculated the change over time using the linear regression model. We compared differences in interest between seasons using the Kruskal-Wallis test with the posthoc Manny-Whitney U test.

The study is a retrospective analysis of the open statistics of search engine queries. Therefore, the project did not require ethical committee approval.

\section{Results}

The median RSV of the PE topic equaled 58.00 (54.00- 


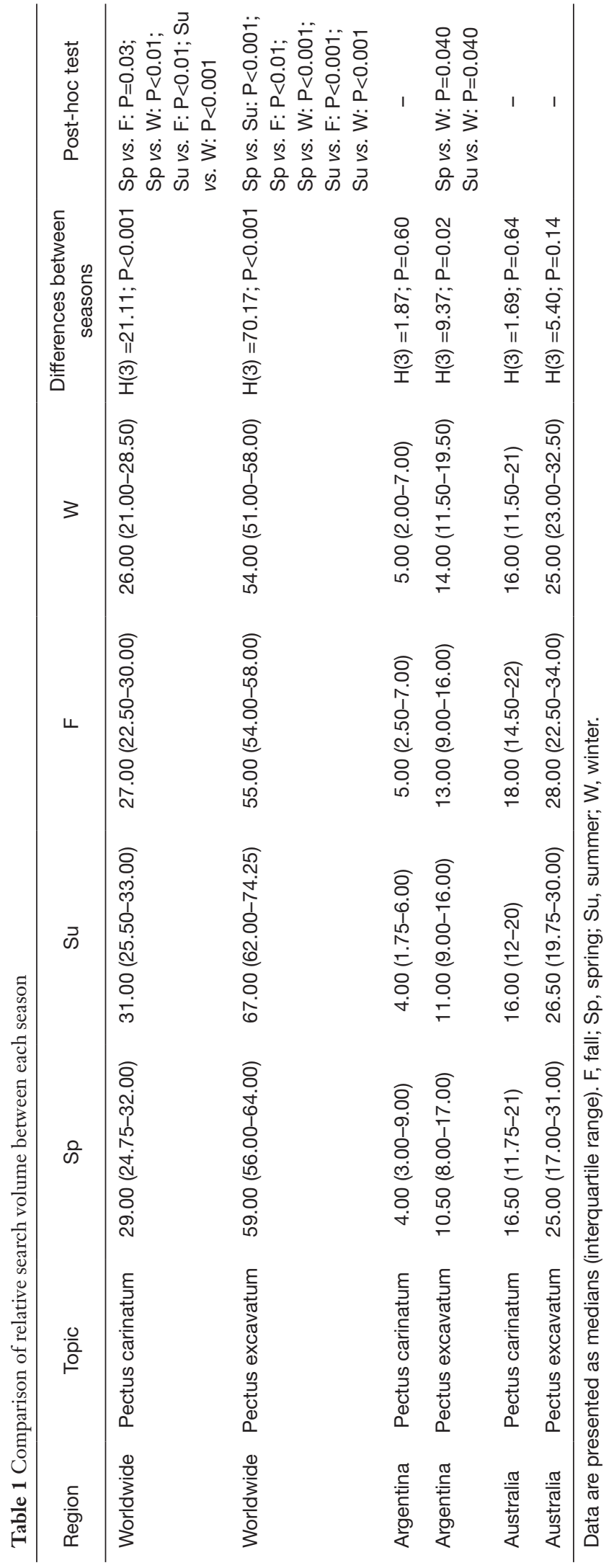

65.00), while for PC it was 28.00 (23.25-31.00). We observed the maximum interest in $\mathrm{PE}$ during October 2008 (RSV $=100.00$ ), while in PC during August 2014 (RSV $=40.00)$.

We observed the highest interest in analyzed topics during summer and the lowest during winter (Table 1). The relative amplitude between summer and winter was equal to $21.4 \%$ for $\mathrm{PE}(\mathrm{P}<0.001)$ and $19.2 \%$ for $\mathrm{PC}(\mathrm{P}<0.001)$. Different seasonal variation was significant for $\mathrm{PE}$ in Argentina, and the relative amplitude was equal to $27.3 \%$ (Table 1).

$\mathrm{PE}$ was the most popular topic in $\mathrm{n}=51$ countries or areas, while $\mathrm{PC}$ in $\mathrm{n}=7$ countries or areas/regions (mainland China, Hong Kong, Iran, Malaysia, Serbia, Sweden, Thailand) (Figure 1). We observed the highest relative interest in PE in Turkey, Austria, Germany, Switzerland, and France, while for PC: mainland China, Thailand, Serbia, Hong Kong, Malaysia and Iran.

The interest in PE decreases on average by $0.98 \mathrm{RSV}$ each year, while interest in PC increased each year by 0.87 RSV (Figure 2). In the forecasted model, the yearly changes were equal to +0.08 for PE and $+0.01 \mathrm{RSV}$ for PC.

The "Nuss procedure" topic had a no-low search volume in $\mathrm{n}=16$, mostly Western countries or areas (Figure 3). PE had a no-low search volume in $n=43$ countries or areas with a simultaneously low search volume for the "Nuss procedure".

\section{Discussion}

We analyzed the secular and seasonal variation, as well as the geographical distribution of interests. We found that the interest of users in $\mathrm{PE}$ is significantly higher than in PC. Moreover, we noticed certain countries or areas where PC is more popular than PE. We documented that the interest in both topics shows seasonal variation. However, the global interest in PC is increasing on a year by year basis. Finally, in some countries or areas we observed a discrepancy between interest in $\mathrm{PE}$ and the Nuss procedure.

We found that Google users' interest in $\mathrm{PE}$ is, on average, two times higher than in PC. Our results are consistent with the epidemiology: $\mathrm{PE}$ is a more common deformity, indicating more significant interest in this defect $(1,2,7)$.

Another notable finding in the present study was that the interest in PE changes annually, while interest in PC increases over time. It may indicate that $\mathrm{PE}$ is slightly losing interest. The possible explanation for this observation may 


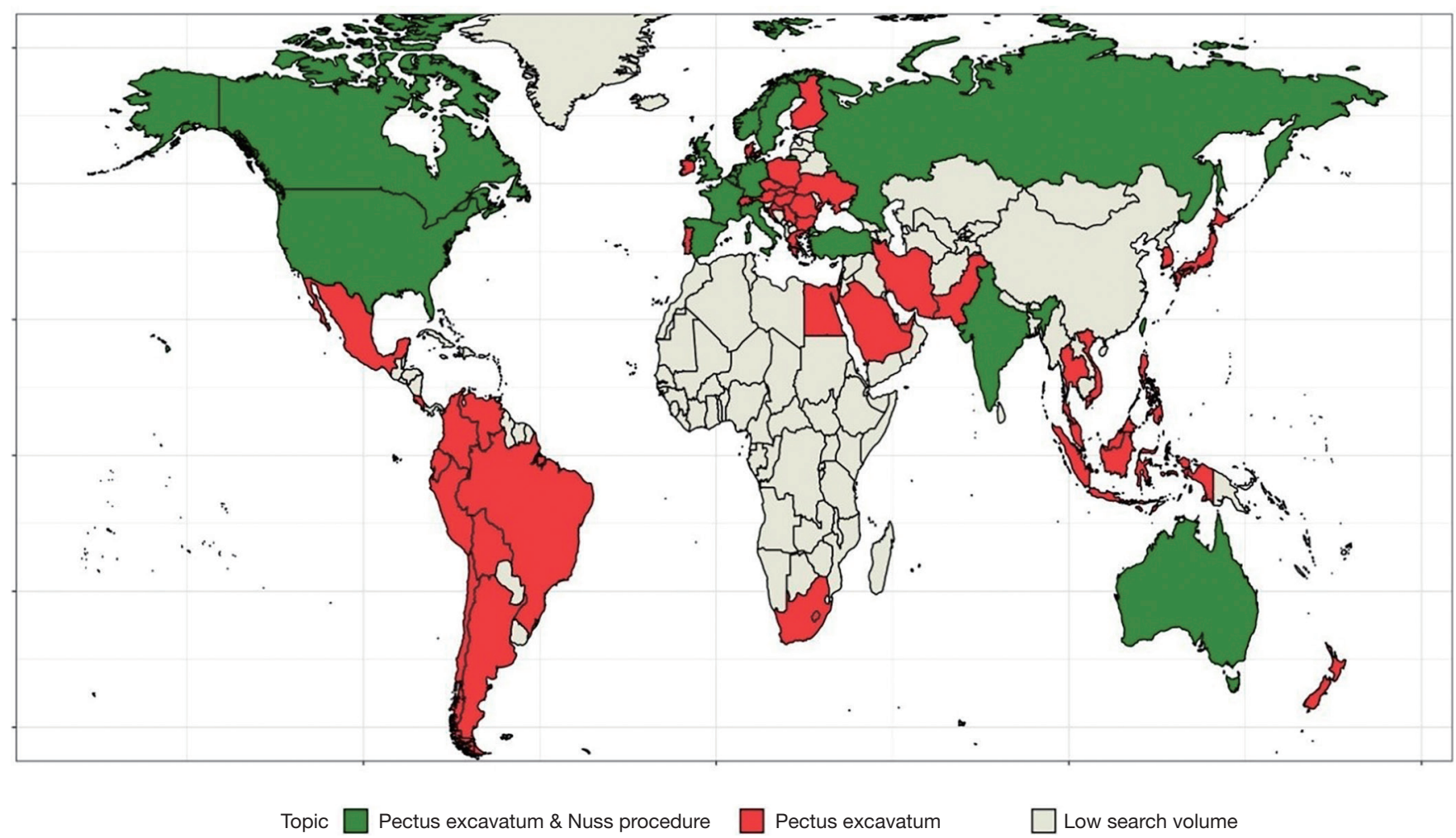

Figure 3 Countries or areas with a no-low search volume from January 2004 through October 2019 for both "Pectus excavatum" and "Nuss procedure" as well as for "Pectus excavatum" only. The gray color represents countries or areas with a low search volume that were not included in the analysis.

be the earlier and better qualification for treatment and more effective, commonly used corrective methods.

Both surgical and non-operative methods are available for the corrective treatment of PE and PC. In the case of PE, treatment is possible through the surgical Nuss procedure. Due to its clinical efficiency and minimal invasiveness, the Nuss procedure became the preferred operative intervention in PE. The Nuss procedure's efficiency for PE exceeds $90 \%$ and gives satisfactory long-term cosmetic outcomes $(6,8,18)$. Despite the high efficiency for PE, in some cases, it is possible to effectively use a vacuum bell, which is a noninvasive treatment method $(19,20)$. Compressive external bracing is a high profile, non-invasive PC treatment method that could succeed in growing patients (21). If this method is insufficient, the available operative methods are the open-surgery Ravitch procedure or the minimally-invasive Abramson technique $(5,22,23)$.

A large part of these procedures is performed by surgeons in specialized centers, access to which in some countries or areas is limited $(24,25)$. The Nuss procedure provides favorable long-term results and heals the chest deformity $(8,18,26-28)$. The recurrence rate is inconsiderable, and most patients have not been further affected $(8,9)$. It is tempting to hypothesize that the Nuss procedure reduces the "pool" of patients with PE. Besides the Nuss technique, in some PE patients, conservative treatment could give favorable results. Techniques like vacuum bell may also allow patients with mild $\mathrm{PE}$ to avoid surgery and explain why PE's interest decreases in some countries or areas. $(19,20)$. The interest in both PE and PC may fluctuate due to the nature of these deformities. They tend to be minimally visible in childhood, worsening during development, and becoming more noticeable in adolescence (5). They significantly reduce the quality of life, cause shyness, apprehension, and could lead to depression $(4,29)$. This is associated with the deformity's perception as a serious bodily defect and results in higher internet interest among adolescents $(10,11)$.

Moreover, the recurrence rate after corrective operations is also an important issue. For example, after using the 
Ravitch technique, it may range from $2 \%$ to even $37 \%$, contrary to the Nuss procedure, which requires a repeat procedure in $0.2-3 \%$ of cases $(28,30-32)$. This is worth highlighting because patients with recurrence may seek a second opinion and help at another surgery center using Google (33).

It is also worth discussing that the highest interest in both deformities shows a seasonal trend. The global interest peaks during summer. It could be related to the number of people and their activity in the Northern Hemisphere. We confirmed our observation, analyzing seasonal variation in two countries or areas from the Southern Hemisphere. In Argentina, the interest in $\mathrm{PE}$ is significantly higher during the Southern Hemisphere's astronomical summer. It can be hypothesized, that the differences between the seasons may be associated with the greater interest in patients' chest appearance during warm months. The untreated deformity may prevent individuals from taking their shirts off during summer activities such as swimming or playing on the beach. This discomfort may motivate some people to search for information related to deformities. It is conceivable to hypothesize, the chance for more accurate and earlier selfdiagnosis is higher in the summer months.

Therefore, greater interest in this problem should result in the wide availability of professional medical and psychological help. In this regard, the pediatrician, the primary care physician, and the psychologists may play a pivotal role in early detection and subsequent, comprehensive patient care.

$\mathrm{PE}$ was the most popular topic in 51 countries or areas, whereas the PC was more popular in 7 countries or areas/regions (mainland China, Hong Kong, Iran, Malaysia, Serbia, Sweden, Thailand). However, this does not correlate with accurate epidemiological data. The Google search engine studies people's interest at a given time and place. It describes the given population's interest in a subject. Unfortunately, research on the global epidemiology of PE and PC is limited and it should be emphasized that the available studies are performed on limited populations. For instance, the prevalence of $\mathrm{PE}$ is $0.23 \%$ in the United States (5), in Iran, the chest deformities affect $1.03 \%$ of the population (34) and in the northern region of Brazil- $1.95 \%$ of the population of 11 - to 14 -year-old students (35). The literature documents a similar incidence of both deformities worldwide and does not indicate geographical location's influence on its occurrence $(7,36,37)$. The complete lack of interest in PE in China and subsequent $100 \%$ of interest in PC is peculiar. It is difficult to explain such a significant difference due to the lack of relevant data on the prevalence of PC and PE in this country. Therefore, it is conceivable to hypothesize that in this case, Google does not match this topic properly.

Moreover, there are no data that would indicate a higher incidence of PC in countries or areas where PC was more popular than PE in GT. It is possible that GT is not a reliable source of information about China due to the fact that most Chinese use other browsers (38). Based on our results, we suggest a more thorough epidemiological study in 7 countries or areas/regions where PC is the most frequently searched record. A related point to consider is that some studies report lower appearance satisfaction in PC than in $\mathrm{PE}$ (4). In this regard, it would also be interesting to examine how representatives in these countries or areas perceive their bodies in terms of PE and PC.

We documented that there are countries or areas where the Nuss procedure is not well known. Most of the records found come from the Western world. A possible explanation may be that $\mathrm{PE}$ and its treatment methods are not very popular in all countries or areas. It is tempting to hypothesize that it is not a popular method for patients, pediatricians and primary care physicians, who may not know when and where to direct potential patients. The availability of qualified surgery centers, where the Nuss procedure can be performed, could also confirm this observation. The number of patients qualified for surgery increases every year since the introduction of the Nuss bar procedure. This observation is also followed by the enhancing amount of medical papers (31). The total yearly number of performed Nuss procedures increases, but the exact number for the whole world is difficult to determine, particularly for countries or areas of the Southern Hemisphere (18). It is also possible that the Google search engine cannot identify "Nuss procedure" records in some languages, for example, Chinese.

In addition, the Ravitch procedure is not recognized at all by GT as a topic. There can be several explanations for this observation. Firstly, this topic refers to a small branch of medicine, which is used only by specialists and is not popular among potential patients. Secondly, the Ravitch procedure may lose interest due to the increasing popularity of non-operative or minimally-invasive methods such as the Dynamic Compressor System or Abramson technique $(5,22)$.

The results are interesting and demand further more detailed studies. The decent quality content on PE and PC may be crucial. Good quality content expands the 
coverage of given topics. Users eagerly discuss, link, or simply share data, once well-written articles are available. Texts that are precisely tailored to readers' needs to solve specific problems and correspond to users' intentions when entering the phrase in the search engine. GT helps investigate unknown seasonal relationships-in this case, seasonal variability and changing interest in $\mathrm{PC}$ and $\mathrm{PE}$. These are little-known phenomena, which can be logically explained. It is further seen that there are still many places where people are interested in PE, while the Nuss method receives a much lower degree of interest. Finally, our data reveal that people use GT; therefore, high-quality internet content is required to make these concepts accessible and better understood.

The authors acknowledge several limitations of this study. Firstly, GT does not provide a precise number of searches and only selects the data for the whole world or a whole country. It is also not possible to choose other macroregions (e.g., the continent). However, RSV is adjusted to the number of Google users in the given region and time. Therefore, the index is useful in analyzing the dynamics of discourse. Secondly, the RSV of the topics could often be dependent on media attention, which could be the reason for a high amplitude of irregularity in some countries or areas (39).

Moreover, the topics with a lower search volume are particularly at risk of irregular variation. This also applies to the analysis of search trends in minor countries or areas. Therefore, investigation of the analyzed topics in Argentina and Australia is limited due to the vulnerability of the trends to irregular variations. Another problem is the inability to confront the internet interest with relevant epidemiology or the exact number of Nuss procedures in the individual countries or areas. Generally, there is no enough data on the epidemiology of both deformities in individual countries or areas and the number of Nuss procedures performed annually. Therefore, confrontation and more detailed discussion are limited. Also, GT does not record data concerning Google users such as gender, age, education, etc., which are the domain of epidemiological research. Finally, Google is not a search engine used by all internet users on the market. The differences can be seen in Europe, the USA, or Japan, where the percentage of Google users is higher, while in countries or areas like Russia or China, it is significantly lower (40). For example, Google's share in the search engine market decreased from $95 \%$ in 2009 to about $3 \%$ in 2019. At the moment, Baidu is the most popular search engine in China, shares $68.66 \%$ of the market.

\section{Conclusions}

Globally, interest in PE is higher than the interest in PC that might reflect real-world prevalence. The Internet is an important source of information on chest wall deformities. Further studies should focus on the quality of websites on PE or PC. GT is an easy-to-use tool that explores the global interest in medical topics, which may provide background for further real-world studies.

\section{Acknowledgments}

Funding: None.

\section{Footnote}

Conflicts of Interest: All authors have completed the ICMJE uniform disclosure form (available at http://dx.doi. org/10.21037/jtd-20-2924). The authors have no conflicts of interest to declare.

Ethical Statement: The authors are accountable for all aspects of the work in ensuring that questions related to the accuracy or integrity of any part of the work are appropriately investigated and resolved.

Open Access Statement: This is an Open Access article distributed in accordance with the Creative Commons Attribution-NonCommercial-NoDerivs 4.0 International License (CC BY-NC-ND 4.0), which permits the noncommercial replication and distribution of the article with the strict proviso that no changes or edits are made and the original work is properly cited (including links to both the formal publication through the relevant DOI and the license). See: https://creativecommons.org/licenses/by-nc-nd/4.0/.

\section{References}

1. Brochhausen C, Turial S, Müller FKP, et al. Pectus excavatum: history, hypotheses and treatment options. Interact Cardiovasc Thorac Surg 2012;14:801-6.

2. McHam B, Winkler L. Pectus Carinatum (Pigeon Chest). In: StatPearls [Internet]. Treasure Island (FL): StatPearls Publishing, 2019 [cited 2019 Nov 11]. Available online: http://www.ncbi.nlm.nih.gov/books/NBK541121/

3. Pawlak K, Dyszkiewicz W. History of cardiac and thoracic surgery: A historical outline of surgical treatment for congenital chest wall deformities. Kardiochirurgia i Torakochirurguia Polska 2013;10:182-5. 
4. Steinmann C, Krille S, Mueller A, et al. Pectus excavatum and pectus carinatum patients suffer from lower quality of life and impaired body image: a control group comparison of psychological characteristics prior to surgical correction. Eur J Cardiothorac Surg 2011;40:1138-45.

5. Martinez-Ferro M, Bellia Munzon G, Fraire C, et al. Nonsurgical treatment of pectus carinatum with the FMF® Dynamic Compressor System. J Vis Surg 2016;2:57.

6. Luo L, Xu B, Wang X, et al. Intervention of the Nuss Procedure on the Mental Health of Pectus Excavatum Patients. Ann Thorac Cardiovasc Surg 2017;23:175-80.

7. Fonkalsrud EW. Management of pectus chest deformities in female patients. Am J Surg 2004;187:192-7.

8. Pawlak K, Gąsiorowski Ł, Gabryel P, et al. Early and Late Results of the Nuss Procedure in Surgical Treatment of Pectus Excavatum in Different Age Groups. Ann Thorac Surg 2016;102:1711-6.

9. Pawlak K, Gąsiorowski Ł, Gabryel P, et al. Video-assistedthoracoscopic surgery in left-to-right Nuss procedure for pectus excavatum for prevention of serious complications technical aspects based on 1006 patients. Wideochir Inne Tech Maloinwazyjne 2018;13:95-101.

10. Protopapas AD, Athanasiou T. Peri-operative data on the nuss procedure in children with pectus excavatum: independent survey of the first 20 years' data. J Cardiothorac Surg 2008;3:40.

11. Nuti SV, Wayda B, Ranasinghe I, et al. The use of google trends in health care research: a systematic review. PLoS One 2014;9:e109583.

12. Mikołaj K, Igor $€$, Wojciech M. Global Internet Data on the Interest in Antibiotics and Probiotics Generated by Google Trends. Antibiotics (Basel) 2019;8:147. Erratum in: Antibiotics (Basel). 2019 Oct 22;8(4):190. doi: 10.3390/ antibiotics 8040190 .

13. Search Engine Market Share in 2019 [Internet]. Oberlo. Available online: https://www.oberlo.com/statistics/searchengine-market-share

14. Kamiński M, Skonieczna-Żydecka K, Nowak JK, et al. Global and local diet popularity rankings, their secular trends, and seasonal variation in Google Trends data. Nutrition 2020;79-80:110759.

15. Kamiński M, Łoniewski I, Marlicz W. "Dr. Google, I am in Pain"-Global Internet Searches Associated with Pain: A Retrospective Analysis of Google Trends Data. Int J Environ Res Public Health 2020;17:954.

16. Forecasting Functions for Time Series and Linear Models n.d. Available online: https://pkg.robjhyndman.com/ forecast/ (accessed 28th November, 2019).
17. McLeod AI, Kendall rank correlation and Mann-Kendall trend test, (2011). Available online: https://cran.r-project. org/web/packages/Kendall/Kendall.pdf

18. Nuss D, Kelly RE, Croitoru DP, et al. A 10-year review of a minimally invasive technique for the correction of pectus excavatum. J Pediatr Surg 1998;33:545-52.

19. Obermeyer RJ, Cohen NS, Kelly RE, et al. Nonoperative management of pectus excavatum with vacuum bell therapy: A single center study. J Pediatr Surg 2018;53:1221-5.

20. Haecker FM, Mayr J. The vacuum bell for treatment of pectus excavatum: an alternative to surgical correction? Eur J Cardiothorac Surg 2006;29:557-61.

21. Jung J, Chung SH, Cho JK, et al. Brace Compression for Treatment of Pectus Carinatum. Korean J Thorac Cardiovasc Surg 2012;45:396-400.

22. Suh JW, Joo S, Lee GD, et al. Minimally Invasive Repair of Pectus Carinatum in Patients Unsuited to Bracing Therapy. Korean J Thorac Cardiovasc Surg 2016;49:92-8.

23. Varela P, Torre M. Thoracoscopic cartilage resection with partial perichondrium preservation in unilateral pectus carinatum: preliminary results. J Pediatr Surg 2011;46:263-6.

24. Yendamuri S. Thoracic surgery in India: challenges and opportunities. J Thorac Dis 2016;8:S596-600.

25. Eberth JM, Crouch EL, Josey MJ, et al. Rural-Urban Differences in Access to Thoracic Surgery in the United States, 2010 to 2014. Ann Thorac Surg 2019;108:1087-93.

26. Tikka T, Steyn R, Bishay E, et al. Short and long term outcomes of pectus surgery. Eur Respir J 2015;46:OA1741.

27. Kelly RE, Shamberger RC, Mellins RB, et al. Prospective multicenter study of surgical correction of pectus excavatum: design, perioperative complications, pain, and baseline pulmonary function facilitated by internet-based data collection. J Am Coll Surg 2007;205:205-16.

28. Kelly RE, Goretsky MJ, Obermeyer R, et al. Twentyone years of experience with minimally invasive repair of pectus excavatum by the Nuss procedure in 1215 patients. Ann Surg 2010;252:1072-81.

29. Sharma G, Carter YM. Pectus Excavatum. In: StatPearls [Internet]. Treasure Island (FL): StatPearls Publishing, 2020 [cited 2020 7th March]. Available online: http://www. ncbi.nlm.nih.gov/books/NBK430918/

30. Guo L, Mei J, Ding F, et al. Modified Nuss procedure in the treatment of recurrent pectus excavatum after open repair. Interact Cardiovasc Thorac Surg 2013;17:258-62.

31. Nuss D, Obermeyer RJ, Kelly RE. Nuss bar procedure: past, present and future. Ann Cardiothorac Surg 
2016;5:422-33.

32. Mansour KA, Thourani VH, Odessey EA, et al. Thirtyyear experience with repair of pectus deformities in adults. Ann Thorac Surg 2003;76:391-5; discussion 395.

33. Chung CS, Myrianthopoulos NC. Factors affecting risks of congenital malformations. I. Analysis of epidemiologic factors in congenital malformations. Report from the Collaborative Perinatal Project. Birth Defects Orig Artic Ser 1975;11:1-22.

34. Rajabi-Mashhadi MT, Ebrahimi M, Mobarhan MG, et al. Prevalence of Chest Wall Deformities in a Large Sample of Iranian Children Aged 7-14 Years. Iran J Pediatr 2010;20:221-4.

35. Westphal FL, Lima LC, Lima Neto JC, et al. Prevalence of pectus carinatum and pectus excavatum in students in the city of Manaus, Brazil. J Bras Pneumol 2009;35:221-6.

36. Ma IT, Rebecca AM, Notrica DM, et al. Pectus excavatum in adult women: repair and the impact of prior or concurrent breast augmentation. Plast Reconstr Surg 2015;135:303e-312e.

37. Robicsek F, Watts LT. Pectus carinatum. Thorac Surg Clin 2010;20:563-74.

38. Top 7 Most Popular Chinese Search Engines in 2019 [Internet]. [cited 2019 Dec 10]. Available online: https:// qpsoftware.net/blog/top-chinese-search-engines

39. Cervellin G, Comelli I, Lippi G. Is Google Trends a reliable tool for digital epidemiology? Insights from different clinical settings. J Epidemiol Glob Health 2017;7(3):185-9.

40. Capala M. Global Search Engine Market Share for 2018 in the Top 15 GDP Nations [Internet]. Medium. 2018 [cited 2019 Dec 11]. Available online: https://medium.com/@ SearchDecoder/global-search-engine-market-share-for2018-in-the-top-15-gdp-nations-2cf65c11e5f5

Cite this article as: Skrzypczak P, Kamiński M, Pawlak K, Piwkowki C. Seasonal interest in pectus excavatum and pectus carinatum: a retrospective analysis of Google Trends data. J Thorac Dis 2021;13(2):1036-1044. doi: 10.21037/jtd-20-2924 